\title{
Religião, "espírito público" e patriotismo na independência do Rio da Prata*
}

Religion, "public spirit" and patriotism during the independence of Rio de la Plata

\section{Geneviève Verdo}

Maître de conférences en Histoire contemporaine à l'Université de Paris I - Panthéon-Sorbonne et membre de I'UMR 8168 "Mondes Américains, Sociétés, Circulations, Pouvoirs - XVème-XXlème siècle" (Mascipo) e-mail: genevieve.verdo@univparis1.fr

Uma primeira versão deste trabalho foi apresentada no seminário do Grupo de Estudios de Historia de la Iglesia, siglos XVIII y XIX (Religión), em Buenos Aires, em 1 de novembro de 2013. Agradecemos vivamente às organizadoras e aos participantes deste seminário por seus comentários, assim como a Ignacio Martínez por sua releitura e precisas sugestões.

\section{Resumo}

Este artigo trata da formação de um patriotismo revolucionário durante a independência do Rio da Prata, e analisa seus fundamentos religiosos. A hipótese aqui defendida é a de que são discursos e rituais da religião católica que permitem a formação de um "espírito público" impulsionado pelo poder revolucionário e pelo patriotismo espontâneo das cidades. 0 artigo evidencia o papel desempenhado por clérigos nesse processo, e a importância de cerimônias cívicas como lugar de expressão de tal patriotismo ao longo dos anos 1812-1814, quando o esforço de guerra se intensifica no Rio da Prata, e quando o controle do poder central é reforçado junto às províncias da região.

\section{Abstract}

This articles deals with the development of a revolutionary patriotism during the independence of the River Plate region and analyzes its religious basis. The hypothesis proposed here is that speeches and rituals of the Catholic religion allow the formation of a "public spirit" stimulated by the revolutionary power and by the spontaneous patriotism of the cities. The article highlights the role played by clergy in this process and the importance of civic ceremonies as an expression of such patriotism over the years 1812-1814, as the war effort intensifies in the River Plate, and when the central power control is reinforced along the provinces of the region.

\section{Palavras-chave}

Rio da Prata, Religião católica, patriotismo, revolução, discursos, cerimônias, clero

\section{Keywords}

River Plate, Catholic religion, patriotism, revolution, speeches, ceremonies, clergy. 
DI STEFANO, Roberto. Política y religión: problemas conceptuales del estudio de sus vínculos durante la primera mitad del siglo XIX argentino. Sociedad y Religión, v. 18, n. 28/29, 2007, p.127-135

CHIARAMONTE, José Carlos. La llustración en el Río de la Plata. Cultura eclesiástica y cultura laica durante el Virreinato, Puntosur. Buenos Aires, 1989; DI STEFANO, Roberto (dir.), Los curas de la Revolución. Buenos Aires: Emecé, 2004; El púlpito y la plaza. Clero, sociedad y política de la monarquía católica a la república rosista. Buenos Aires: Siglo XXI, 2004.

3

DEMÉLAS-BOHY, Marie-Danielle. La guerra religiosa como modelo. In: GUERRA, FrançoisXavier. (dir.), Las revoluciones hispánicas: independencias americanas y liberalismo español. Complutense: Madri, 1995, p.144164; _. Politicas sacadas de las sagradas escrituras. La referencia a la Biblia en el debate politico (siglos XVII a XIX). In: QUIJADA Mónica; BUSTAMANTE, Jesús (ed.). Élites intelectuales y modelos colectivos. Mundo ibérico (siglos XVI-XIX). Madri: CSIC, 2002, p.155-198; IRUROZOUI, Marta. El sueño del ciudadano. Sermones y catecismos políticos en Charcas tardocolonial. In: . Op. Cit. p.219-249; LEMPÉRIĖRE, Annick. Entre Dieu et le Roi, la République. Mexico, XVle-XIXe siècle. Paris, Flamarion, 2005; PERALTA RUIZ, Victor. Sermones y pastorales frente a un nuevo lenguaje político. La Iglesia y el liberalismo hispánico en el Perú (1810-1814). In: HÉBRARD, Véronique; VERDO, Geneviève (dir.). Les indépendances hispanoaméricaines, un objet d'histoire. Madri: éditions de la Casa de Velázquez, p.117-132.

Para o caso francês, cf. DE VIGUERIE, Jean. Étude sur l'origine et sur la substance du patriotisme révolutionnaire. Revue Historique, n. 597, 1996 p.83-104.
A questão das relações entre os poderes civis e religiosos, e de sua progressiva separação, constitui um dos principais desafios do advento da modernidade política nas sociedades ocidentais. Esse problema, que se inscreve na longa duração, propiciou conflitos memoráveis e seus desdobramentos permanecem fortemente atuais. No que concerne ao período das revoluções atlânticas (fim do século XVIII, início do XIX), o exemplo francês constitui um espelho deformante, pois as tendências presentes alhures na Europa atingem, nele, um ponto extremo de radicalidade. No curso da Revolução Francesa, apesar da diversidade de correntes que compunham a hierarquia eclesiástica, a religião católica sofre, em seu conjunto, do descrédito da Igreja, inteiramente assimilada ao Antigo Regime, tanto por causa de seu caráter hierárquico, quanto pelo vínculo que a unia ao poder real. Nesse sentido, contudo, como também noutros aspectos, a França constitui um caso excepcional, na medida em que, ali, a centralização administrativa foi relativamente forte ao longo do século XVIII, permitindo ao Estado impor sua soberania a todos os setores da sociedade, inclusive aos corpos eclesiásticos. ${ }^{1}$

0 caráter paradigmático frequentemente associado ao exemplo francês teve por corolário ocultar, durante algum tempo, a importância da religião em outras culturas políticas, particularmente aquelas do mundo hispânico. Todavia, este campo encontra-se atualmente em plena renovação: um melhor entendimento da cultura católica das Luzes, de seus atores e de seus conflitos acarreta uma nova perspectiva sobre o período revolucionário, ${ }^{2}$ ao mesmo tempo em que a importância da religião no imaginário patriótico do período ganha uma abordagem renovada. Ao lado de outros especialistas do mundo hispânico, ${ }^{3}$ os historiadores do fenômeno religioso na Argentina demonstraram, com efeito, que a religião e os membros do clero estavam presentes em todos os momentos do processo revolucionário, e que a cultura católica era um elemento indispensável à compreensão dos imaginários e das culturas políticas da época.

0 lugar primordial ocupado pela Igreja e pela religião católica no processo das revoluções ibéricas se explica não somente pela cultura das elites, tocadas pela llustración católica, mas, igualmente, pelas circunstâncias na origem da mutação política. De uma parte à outra do Atlântico, a invasão napoleônica da Espanha teve por_consequência revelar os elementos mais profundos daquilo que podia passar por "nacionalidade" hispânica e exacerba o elemento religioso na gênese do patriotismo: tanto na Espanha peninsular quanto no império, trata-se de salvar a pátria e de proteger os direitos do rei, o que acarreta a defesa da "verdadeira fé" face aos abusos e à impiedade da França revolucionária.

No caso do Rio da Prata, o principal problema com que se defrontam os dirigentes a partir de 1810 consiste em dotar sua autoridade de fundamentos legítimos, preservando, com isso, a unidade do vice-reino. Sua principal tarefa consiste, então, em reforçar a união dos pueblos e sua adesão à "causa comum" por meio da promoção de um conjunto de valores que podemos qualificar de "espírito público", por analogia com a França revolucionária. Esta empresa de propaganda distingue-se do patriotismo manifestado pelas cidades: aferrado a uma identidade local, este se traduz pela adesão às autoridades e à Pátria, entidade nova que não corresponde mais à Monarquia, mas à América patriota, e que funda um pertencimento comum. ${ }^{4}$ É diante desse quadro que convém se perguntar sobre o papel atribuído aos clérigos e à religião na formação desse patriotismo. É, com efeito, 
por meio dos discursos e dos rituais da religião católica (festas patronais e sermões) que o "espírito público" promovido pelas autoridades se exprime e se articula com o patriotismo local. Zelosos na devoção à causa, os vecinos de diferentes cidades recebiam, assim, a mensagem revolucionária por meio do elemento religioso, integrando-a a rituais de adesão preexistentes.

0 estudo que se segue será centrado no período que vai de 1812 a 1814, quando o esforço de guerra se intensifica nas Províncias Unidas e 0 regime revolucionário acentua seu controle sobre as cidades. Estas, então, encontram no patriotismo um escoadouro para seu desejo de ostentação e de representação, permitindo a recepção, por meio da religião, dos valores e da orientação política que o regime entende impulsionar.

I - Do "espírito público" ao patriotismo: a criação de uma consciência coletiva sob a Revolução

Costuma-se fazer coincidir o processo revolucionário no Rio da Prata com a criação da Junta de 25 de maio de 1810. Embora composta por elementos radicais, esta recupera, a seu beneficio, a legitimidade das autoridades tradicionais e, particularmente, aquela do rei Fernando VII, da qual ela pretende "conservar os direitos" frente ao perigo que representa Napoleão. Este esforço de legitimação permite-Ihe se fazer reconhecer pelas diversas cidades do vice-reino (com a exceção das jurisdições de Montevidéu, Assunção e do Alto-Peru), às quais ela promete, em contrapartida, a criação de uma assembleia constituinte. A representação das cidades é, então, aquilo que funda, ao longo de todo o período, sua adesão ao poder instalado em Buenos Aires. Esta nomeia governadores devotados à "causa" nas cidades, encarregados, entre outros, de supervisionar a opinião e de difundir a mensagem revolucionária.

No curso dos anos seguintes, esse poder central adopta inicialmente uma forma coletiva com a Junta Grande (dezembro de 1810), e depois evolui rumo a uma centralização cada vez mais impulsionada com a criação do Triunvirato, que dissolve a Junta em novembro de 1811. Este mesmo ano de 1811 é marcado pelos primeiros reveses militares da revolução, que perde 0 controle do Paraguai e é atacada pelos realistas em Montevidéu e no Alto Peru. 0 contexto da guerra, assim como a evolução da situação na Espanha, com a promulgação da Constituição de Cádis, explica porque o ano 1812 constitui um ponto de virada a partir do qual dois campos se desenham. Nessa data, a figura do rei termina de perder sua legitimidade, enquanto o Rio da Prata é considerado pelas autoridades espanholas como uma região insurgida. Em resposta a isso, os contrarrevolucionários e, notadamente, os espanhóis europeus, são estritamente vigiados e conhecem a proscrição do regime. Além disso, o enfrentamento ideológico e militar leva o poder central a reforçar seu poder sobre as cidades, que haviam afirmado, em 1811, uma tendência à autonomia. 0 acento é colocado nos discursos sobre os perigos que ameaçam o pais, justificando a tomada de medidas autoritárias e uma vigilância acirrada da opinião. É nesse contexto que o poder estabelece disposições específicas para promover o "espírito público", o qual deve ser distinguido do patriotismo manifestado pelos habitantes das cidades de maneira mais ou menos espontânea, sobretudo durante cerimônias patrióticas, e segundo um registro que evolui ao longo do período.

a) 0 "espírito público" ou o enquadramento ideológico das populações Se a encontramos nas fontes em sua tradução espanhola (espíritu público), a expressão "espírito público" pertence à linguagem da revolução francesa 
BAKER, Keith Michael. Esprit public. In: OZOUF, Mona; FURET, François (dir.). Dictionnaire critique de la Révolution Française. Paris: Flamarion, 1992, p.165-180.

6

Oficio del Superior Gobierno a los cabildos, 27/11/1811, Archivo Histórico de Mendoza, sección Independiente (AHM Ind.), 602-114.

7

Oficio del gobernador de Tucumán al Superior Poder Executivo, 22/02/1813; Oficio del cabildo de Tucumán al Teniente-gobernador, 9/04/1813, Archivo General de la Nación (AGN), Gobierno de Tucumán (Gob. Tuc.), X-5-10-1.

8

Oficio del Superior Gobierno al cabildo de Tucumán, 6/11/1812, Archivo Histórico de Tucumán, sección Administrativa (AHT Adm.), 22-328. e, mais especificamente, ao esforço conduzido pelos jacobinos para impor, por meio desse conceito, "o sonho arcaico de uma unidade perfeita da comunidade e de suas guildas, de uma absorção completa dos indivíduos na cidadania". ${ }^{5} \dot{E}_{1}$ com efeito, durante a ditadura jacobina (1792-1795) que a liberdade da imprensa se vê restrita, a diversidade das opiniões devendo ceder espaço à constituição, desde o topo do poder, de um pensamento unânime, que deveria refletir a unidade social.

No Rio da Prata, os partidários de Mariano Moreno (principal membro da Junta de Maio, precocemente falecido em 1810), cujos adversários os tratavam de "jacobinos", efetivamente se inspiraram em certas ideias em vigor na revolução francesa. Quando eles obtêm o poder a partir da criação do Triunvirato em 1811, eles retomam por si mesmos a ideia de forjar uma opinião unânime "a partir de cima", a fim de salvaguardar a unidade das províncias e de fazer o conjunto dos cidadãos compartilhar os valores e princípios defendidos pelo novo regime.

A formação da opinião aparece, assim, como o reverso positivo da vigilância que as autoridades devem exercer sobre as populações. Nas cidades, os governadores repercutem o tipo de discurso e os temas que lhes chegam pelos filtros oficiais. Estes têm por vezes uma aparência de verdadeiros catecismos revolucionários, como o mostra a circular que acompanha o Estatuto provisório de novembro de 1811:

\begin{abstract}
Los dos puntos que deben, en todo tiempo y estado, empeñar el celo de los Pueblos para su libertad son: el que el depósito de la autoridad no llegue jamás a ser caudal propio de ningún ciudadano, y que el goce de los tres primeros derechos del hombre, propiedad, seguridad y libertad esté, bajo reglas ciertas, afianzado respecto de todo individuo. Estos son cabalmente los dos bienes fecundos que tiene la satisfacción este Gobierno de ofrecer a todos los Pueblos de su mando en el Estatuto impreso que acompaña a VS. ${ }^{6}$
\end{abstract}

Esses textos oficiais são complementados pela Gazeta de Buenos Aires, órgão oficial do governo. Se os dirigentes por vezes recomendam expressamente de o fazer circular entre os "chefes e as corporações", isto é, os principais vecinos, os relatos dos eventos e os debates de ideias são seguidos com interesse nas cidades. Entretanto, os jornais somente são divulgados depois de devidamente fiscalizados pelas autoridades, que temem acima de tudo a propagação de escritos subversivos.?

Enfim, o ativismo patriótico é ele próprio defendido e praticado, notadamente nas ocasiões excepcionais, tais como a campanha que Belgrano prepara no fim de 1812. Naquela ocasião, o Triunvirato exorta o cabildo de Tucumán nestes termos:

\footnotetext{
[La Patria] reclama hoy imperiosamente el que VS estimule y aliente el entusiasmo acreditado de los dignos Tucumanos para que sigan los pasos del Ejército [del norte], mezclados entre sus compatriotas, hasta triunfar del opresor de Salta. (...) Recomienda a VS este Gobierno que, penetrado de la grande importancia de la campaña, inflamará el generoso ánimo de los valientes ciudadanos, decidiéndoles a dar nuevos días de gloria a la Patria, y arruinar de un golpe el despotismo, y aun las esperanzas de sus enemigos. ${ }^{8}$
}

Os membros do cabildo respondem no mesmo tom, evocando os recrutamentos efetuado e "el entusiasmo que han difundido en el distrito (...) encargando a los curas rurales para que por medio de sus exhortaciones elec- 
9

Oficio del cabildo de Tucumán al Superior Gobierno, 24/11/1812, AGN Gob. Tuc., X-5-10-1.

10

Bando del Teniente-gobernador de Mendoza, 5/01/1813, AHM Ind., 4-7. Grifos nossos.

11 Bando de Juan Florencio Terrada, 29/01/1814, AHM Ind., 4-10. Grifos nossos.

12

Oficio del cabildo de Santiago del Estero al cabildo de Tucumán, 7/08/1813, AHT Adm., 23-272.

13

Oficio de Juan de la Cruz Vargas al Tenientegobernador, 8/01/1813, AHM Ind., 235-1;

14

Oficio del cabildo al Teniente-gobernador 9/01/1813, AHM Ind., 746-18; Oficios de José Maria García y de Juan Martínez de Rozas al Teniente-gobernador, 13/01/1813, AHM Ind. 234-25 et 26

15

Oficio del Teniente-gobernador al Superior Poder Executivo, 2/02/1813, AGN Gobierno de Mendoza (Gob. Men.), X-5-5-11. Na sequência dessa criação, as fontes não mencionam mais esta instituição. A morte do presidente Juan Martinez de Rozas, alguns meses depois, talvez marque 0 fim da experiência. trijen al paisanaje, lo animen a seguir en sus caballos al Ejercito y que llenen la medida de glorias que habian estado destinadas al suelo de Tucumán".

Face às divisões que mitigam sua autoridade e ameaçam a ordem pública, os governos continuam a defender a união e a obediência devida ao governo. Seus discursos prestam testemunho de um combate ideológico destinado a defender a doutrina sustentada pelos dirigentes, como o mostra este decreto do governador de Mendoza, publicado em maio de 1813:

Por cuanto el espíritu público se halla casi extraviado, y aniquilado por la diversidad de opiniones, entre sí contrarias, y destructoras del sistema de la libertad nacional, no podrá ningún individuo de cualesquiera clase, o dignidad que sea, atacar la justicia de nuestra causa, por hallarse ya sancionada por la opinión imparcial, y por la general de América, bajo la pena de ser tratado como reo del estado. ${ }^{10}$

No mesmo sentido, seu sucessor, Juan Florencio Terrada, intimou os vecinos a sepultar suas querelas e a trabalhar em conjunto pela causa comum:

\begin{abstract}
Deseando el presente Gobierno, que entre los habitantes de esta Ciudad no hayan divisiones ni partidos, que solo haya una opinión, y un sistema, cual es el más justificado que sostiene por la Patria la América del Sud, encargo a todos los vecinos transeúntes y estantes en esta ciudad remitan al olvido cualesquiera resentimientos particulares que se le hayan subsistido por esta u otra causa, y procuren con el último sacrificio la reunión de todos los ciudadanos a sostener un mismo sistema por los principios reclamados de la Libertad, Soberanía e Independencia de la Nación Americana. ${ }^{11}$
\end{abstract}

Esse tipo de retórica modifica-se definitivamente nos anos 1813-1814. As divisões internas, inerentes às sociedades que eles administram, aparecem cada vez mais como a maçã podre no cesto da revolução. Contrariamente à Junta Grande, que havia deixado certa margem de expressão às opiniões específicas dos Pueblos, os membros da Sociedade Patriótica reagem da mesma forma que os jacobinos franceses. Eles pretendem substituir essas opiniões particulares, divergentes e ameaçadoras à ordem social por um "espírito público" unanimista, insuflado pelos altos círculos do Estado e inteiramente orientado para a defesa da unidade. Para este fim, as provas de patriotismo são publicamente louvadas e encorajadas, sendo os dirigentes os primeiros a dar o exemplo. 0 gesto de Belgrano, que oferece sua recompensa para construir escolas nas vilas do interior, é abundantemente comentado, e é considerado modelo de uma conduta virtuosa, desinteressada, inteiramente devotada ao bem comum. ${ }^{12}$

0 exemplo da Sociedade Patriótica, fundada em 1812 pelos partidários de Moreno para forjar e orientar a opinião pública nascente, produz emuladores na província. Em Mendoza, uma Sociedade Literária e Patriótica é fundada sob ordem do Triunvirato em fevereiro de 1813, a fim de formar a opinião dos cidadãos e de propagar "os justos fundamentos sobre os quais repousa o sistema atual de nosso continente americano".13 Essa criação anuncia uma evolução nas relações de poder no seio da cidade, uma vez que os membros do cabildo declaram que eles assistirão às reuniões na condição de "simples cidadãos", ${ }^{14}$ o que supõe um afastamento voluntário da função e das precedências que ela habitualmente implica. Em 2 de fevereiro, a população é convocada em assembleia pelo governador para ratificar essa decisão e eleger os membros da Sociedade. Ao fim da votação, esta é confiada, sem surpresa, a dois homens da lei e a dois homens da Igreja, reconhecidos como os mais aptos a marcar nos espíritos a mensagem da revolução. ${ }^{15}$ 
CHIARAMONTE, José Carlos. Formas de identidad en el Río de la Plata luego de 1810. Boletín del Instituto de Historia Argentina e Americana "Dr. Emilio Ravignani", 3a. série, n. 1, 1989, p.71-91.

17

Bando del cabildo de Salta, agosto de 1810 In: GONZÁLEZ, Julio V. Filiación histórica del gobierno representativo argentino. Buenos Aires: La Vanguardia, 1937, t. 2, p.455.
0 Triunvirato e, por meio dele, a Sociedade Patriótica, instauram assim um regime orientado para a defesa da ordem pública e o ordenamento ideológico das populações. Os governadores, escolhidos por sua fidelidade à equipe dirigente, se esforçam para traduzir essa política em atos. Essa mobilização das populações é o reflexo, no plano ideológico, das exigências da guerra e de uma presença mais marcante do poder central no interior.

b) 0 patriotismo: pretexto à ostentação e substituto da representação A esse patriotismo "oficial" pode-se opor, contudo, o patriotismo "espontâneo" dos pueblos, ele próprio portador de um significado político. De 1810 em diante, o patriotismo manifestado há anos em nome do Rei e da Monarquia começa a evoluir a partir do momento em que os contrarrevolucionários de Córdoba e os agentes da Coroa de origem peninsular (os mandones) tornam-se 0 alvo dos ataques da Junta. Os dirigentes dedicam todos os esforços para que patriotismo e revolução se confundam pouco a pouco no imaginário coletivo.

A partir de 1812, os imperativos militares sobrepõem-se ao conteúdo ideológico, mas o significado do patriotismo permanece idêntico: permitindo às cidades exprimir sua devoção à causa comum ao fazer valer suas qualidades próprias, ele desempenha um papel comparável àquele da representação politica, entendida em seu sentido antigo. Assim, ele permite compreender como o regime controlado a partir de Buenos Aires chega a conservar sua proeminência nas cidades do interior.

\section{Do patriotismo vassálico ao patriotismo americano (1810-1812)}

Em 1810, o imaginário patriótico conserva a aparência dos anos precedentes: trata-se, essencialmente, de um patriotismo de vassalos e de cidades. Os textos de 1810 invocam invariavelmente o Rei e a Pátria, o que remete tanto à Monarquia espanhola quanto ao vice-reino como parte desse conjunto. 0 termo também pode designar a cidade, e ambos os sentidos são às vezes empregados simultaneamente. ${ }^{16} \mathrm{~A}$ convocação do cabildo de Salta a seus habitantes, em agosto de 1810, se estende, assim, a "los altos fines de consecuencia al Rey a la Patria, que se propusó la muy ilustre y valerosa Capital de Buenos Ayres" e termina na perspectiva de juntar "a los timbres con que se decora vuestra Patria el de sabia en sus resoluciones". ${ }^{17}$

0 patriotismo do início da revolução se articula, então, em torno de dois eixos: um horizontal, aquele das comunidades, que conhece diferentes escalas, da cidade à Monarquia, passando pelo reino; o outro, vertical, que religa estas comunidades ao Rei por um vínculo de tipo vassálico. Em virtude deste, cada sujeito e cada comunidade encontra-se vinculada de maneira direta e pessoal, enquanto a reciprocidade do pacto implica que as cidades sejam recompensadas por essa fidelidade que exprimem incansavelmente.

Com a fidelidade e a generosidade, a principal qualidade esperada do vassalo é a subordinação às autoridades legítimas. Resulta disso, em 1810, uma primeira inflexão no conteúdo do patriotismo: este é doravante confundido com a adesão à Junta, na medida em que esta se coloca como representante do Rei e garantidora da Monarquia. 0 novo regime se instala nos quadros da lealdade tradicional, o que permite que esta subsista por algum tempo: ao longo de todo o ano de 1811, a invocação ao Rei permanece nos atos oficiais; seu aniversário continua a ser celebrado, e orações públicas são organizadas pela sua libertação. 0 ano de 1812, porém, é marcado por uma radicalização ideológica e por uma inflexão no que diz 
Oficio de la Junta de Gobierno a la junta subalterna de Mendoza, 1/09/1811, AHM Ind., 602-74; Oficio del Superior Gobierno al cabildo de Tucumán, 6/11/1812, AHT Adm., 22-328. 19

CHIARAMONTE, José Carlos. Formas de identidad. Op. Cit.

20

Manifiesto de la Junta a los pueblos, 09/09/1810. In: CARRANZA, Adolfo P. Archivo General de la República argentina. Buenos Aires, 1894-1898, t. 1, p.230.

21

Oficio de la Junta de Gobierno a la junta subalterna de Mendoza, 01/09/1811, AMH 602-74.

22

VIGUERIE, Jean de. Op. Cit. respeito a Fernando VII, cuja longa ausência erode a legitimidade. Assim, enquanto o vice-rei Elío é acusado em 1811 de "esquecer seus deveres de fiel vassalo da Monarquia espanhola", o general Tristán é qualificado, no ano seguinte, de "Tirano da Pátria".18

A evolução que se opera ao longo dos anos 1810-1812 passa, igualmente, pela distinção entre europeus e americanos. ${ }^{19} \mathrm{~A}$ referência à América já está presente em 1810, mas esta é considerada como uma possessão da Coroa que seus habitantes devem defender, o que se encontra na expressão "esses domínios" (estos domínios). 0 primeiro inimigo designado pela Junta não é propriamente o peninsular, mas o oficial do antigo regime, culpado de ter traído sua missão: "[Los sujetos que han cometido tan graves crimenes] no eran extranjeros a nuestro pais, que en la cegüedad de su empeño pudieran alguna vez mirar con indiferencia nuestras desgracias", escreve a Junta em setembro de $1810 .{ }^{20}$

A distinção começa a aparecer a favor da guerra na Banda oriental, em 1811. A invasão portuguesa é, com efeito, a ocasião de afirmar uma identidade específica à América, não mais como parte da Monarquia, mas como região autônoma, capaz de defender-se por si mesma:

Ha llegado el caso de manifestar a todo el Mundo que en los habitantes de este hemisferio se descubren las mismas virtudes de valor, celo y patriotismo que distinguieron a otros pueblos en iguales circunstancias ${ }^{21}$

É em 1812 que o fosso entre americanos e europeus se amplia definitivamente e que a figura do inimigo se desdobra entre os "inimigos externos", os realistas do Alto Peru e da Banda oriental, e os "inimigos internos", os contrarrevolucionários que multiplicam seus complôs contra o Trinvirato. ${ }^{22} \mathrm{~A}$ descoberta da conspiração de Alzaga "contra a pátria e a liberdade americana", em julho de 1812, é celebrada nas cidades com grande entusiasmo. Esse episódio acarreta uma assimilação entre os dois tipos de inimigos, e constitui um momento importante para a cristalização do sentimento patriótico: na ordem do discurso, os peninsulares são postos à margem da comunidade, e na ordem dos fatos, são os principais alvos do zelo das autoridades.

Essa fratura entre europeus e americanos sanciona o desaparecimento, no interior da maioria das elites, do sentimento de lealdade vassálica pelo Rei: a partir de então, é muito claramente com o governo das Províncias Unidas que se faz aliança. Essa rápida evolução deu-se principalmente por causa da guerra e de seu uso pelo poder em termos ideológicos. Em 1812, a referência patriótica confunde-se com a identidade americana, e os princípios políticos são inteiramente subordinados à luta: trata-se, primordialmente, de obedecer às autoridades e de se sacrificar para defender a terra. Num discurso à população, o governador de Tucumán chama os patriotas de "os legítimos soberanos do Novo Mundo", que fazem soldados "livres, disciplinados e virtuosos". Opõe-se-Ihes o inimigo por excelência a partir dos traços do general Tristán, o "caudilho antiamericano", "o tirano que jurou levar a termo a desolação e o extermínio de cada americano". A transferência das alianças é muito legivel aqui: contra o novo Napoleão representado, sucessivamente, pelos generais do Alto Peru (Tristán ou Goyeneche), não se defende mais os direitos do Rei sobre seus domínios, mas a própria América e seus novos soberanos. 
23

CHIARAMONTE, José Carlos. Formas de identidad. Op. Cit.

24

Circular del Director Supremo, 24/06/1814, Archivo Histórico de Córdoba, fondo de Gobierno (AHC Gobierno), 38-525.

25

Criada em janeiro de 1814, a função de Diretor Supremo substitui o Triunvirato e a concentra nas mãos de um único poder executivo. Seu primeiro titular é Antonio de Posadas, substituído em janeiro de 1815 por seu sobrinho, Carlos de Alvear. 26

Oficios del gobernador y del cabildo de Córdoba al Director Supremo, 2/07/1814, AGN Gobierno de Córdoba (Gob. Cba.), X-5-2-7.
Alem disso, a "construção do sistema atual do continente americano" conjuga a luta contra o absolutismo com a construção de regimes liberais. No interior do antigo vice-reino, a americanidade participa, então, da criação do novo Estado, como o mostra a atribuição sistemática dos postos aos cidadãos das Províncias Unidas. Contudo, como destacou José Carlos Chiaramonte, ${ }^{23}$ as formas de identidade coletiva que se afirmam o mais das vezes a favor da guerra são o pertencimento à cidade e à dimensão americana, mais do que a afiliação a uma pátria que corresponderia ao antigo vice-reinado, espaço de soberania do novo poder.

\section{Do patriotismo revolucionário ao patriotismo militar (1812-1814)} 0 esforço intenso das cidades do Interior a partir de 1812 modifica a natureza da adesão que elas emprestam ao regime e fazem a guerra passar ao primeiro plano de suas preocupações. Desse modo, as formas do pertencimento coletivo se alheiam pouco a pouco do conteúdo ideológico que elas tiveram no início da revolução para se confundir com uma guerra cada vez mais sacralizada.

0 contexto militar dos anos 1813 e 1814 modifica, em primeiro lugar, o conteúdo das celebrações patrióticas, nas quais o tema da guerra cresce em importância. 0 entusiasmo popular e o vínculo ao regime medem-se, a partir de então, pelos progressos das armas patriotas, que marcam os tempos fortes desse calendário festivo.

0 início do ano 1813 é marcado pela batalha de San Lorenzo, vencida por San Martín às portas de Montevidéu em 3 de fevereiro e, sobretudo, pela batalha de Salta, em 20 de fevereiro, quando Belgrano rechaça a invasão do general Tristán. Essas vitórias são estrepitosamente anunciadas nas províncias, sendo essas novidades ocasiões propícias para celebrar o regime. 0 simples anúncio de uma vitória, a despeito do lugar onde ela tenha ocorrido é, então, um meio de fortalecer o vínculo de obediência entre o poder central e seus súditos, mas também entre a capital e as outras cidades.

0 outro grande evento militar do período é a tomada de Montevidéu, em junho de 1814. As cerimônias organizadas em torno desta vitória devem ser lidas como uma tentativa do poder central de restaurar seu prestígio. Com efeito, as celebrações não são nada espontâneas: a ordem de festejar a vitória, dada pela circular de 24 de junho, prescreve os elementos ritualísticos da celebração (salvas, iluminação, sinos, Te Deum), ${ }^{24}$ que são acompanhados pelo relato detalhado da batalha, redigido pelo general vencedor Carlos de Alvear, que deverá ser publicado por meio de aviso público. A vitória é festejada com enorme solenidade até mesmo nas menores cidades, como em La Carlota, na jurisdição de Córdoba.

Deve-se notar que as felicitações não são endereçadas aos militares vitoriosos, mas ao Diretor Supremo, ${ }_{1}^{25}$ que aparece como a encarnação da Pátria e do Estado. Os qualificativos que o designam aliam as virtudes do oficial àquelas do chefe de Estado: assim, o cabildo de Tucumán declara a Posadas que "se unen en su respectable persona el valor y la competencia militar de Washington con la pericia, la sagacidad y la prudente seguridad de Franklin".26 $\mathrm{Na}$ realidade, o prestígio repousa sobre o verdadeiro herói da vitória, Carlos de Alvear, e prepara sua ascensão ao poder alguns meses mais tarde.

\section{c) 0 patriotismo como forma de ostentação}

A julgar pelas descrições das cerimônias, parece que o patriotismo, tal como ele é vivido e interpretado pelas cidades, oferece o pretexto para 
27

Oficio del cabildo de Buenos Aires al de Tucumán, 26/10/1812, AHT Adm., 22-322. Cf. WILDE, Ana. La Batalla de Tucumán y sus representaciones rituales 1812-1853. Jornadas 1812. Tucumán en la independencia. Nuevas miradas sobre 1812: actores, prácticas y rituales de una ciudad en guerra. Tucumán, 15 e 16/ out/2012. Nós agradecemos à autora por nos ter permitido utilizar seu texto.

28

Aviso del Superior Gobierno, 26/11/1812, AHT Adm., 22-376. uma certa ostentação. A identidade de uma cidade passa, com efeito, pelos títulos e pelas qualidades que se the outorguem ou que ela própria se atribua. Ora, o contexto de crise, depois de guerra, oferece às cidades do Rio da Prata uma magnífica possibilidade de fazer valer seus méritos. A atitude política de uma comunidade é diretamente interpretada à luz de suas qualidades, cuja evocação torna-se passagem obrigatória do discurso oficial. Essas virtudes, que os textos governamentais e os sermões patrióticos não cessam de exaltar, sempre remetem ao modelo da vassalidade: a obediência às autoridades superiores, a fidelidade à palavra dada, a generosidade na ajuda oferecida são os critérios à luz dos quais são julgados tanto os indivíduos quanto as comunidades.

As manifestações desse patriotismo das cidades evolui em função do contexto. Durante os primeiros anos, a doação voluntária constitui certamente o gesto mais revelador na manifestação do patriotismo, porque ele exprime, ao mesmo tempo, a generosidade e a submissão às autoridades. Vir em auxilio do Rei ou do governo permite às diferentes cidades, como a cada um de seus membros, rivalizar com as outras sem pretender dominá-las. Outra circunstância que oferece às cidades a oportunidade de demonstrar seu zelo patriótico é aquela das cerimônias, que tendem a se multiplicar com o surgimento do novo regime. Enfim, o triunfo que pode enobrecer a cidade atinge seu apogeu quando ela é parte ativa dos eventos militares, pois a guerra é o que dá seu sentido e motiva profundamente 0 patriotismo nascente das Províncias Unidas.

Nesse sentido, Tucumán ocupa um lugar completamente excepcional durante 0 ano 1812. Após a vitória de 24 de setembro, um culto patriótico se organiza na cidade por iniciativa de Belgrano: uma procissão se desenrola sobre o campo de batalha onde ocorre a comemoração, enquanto a Virgem das Mercedes, cuja festa coincide com o dia da vitória, é nomeada "General do Exército". Nessa ocasião, a cidade se vê coberta de elogios pelo Triunvirato e pelo Cabildo de Buenos Aires:

\footnotetext{
Esta acción es de aquellas, cuya extraordinaria grandeza (...) no puede elogiarse bien sino con el silencio expresivo de la admiración. Y mientras los pueblos todos del continente americano tributan este honroso homenaje al que VS representa, este Cabildo lo congratula por ello cordialmente, y se da los parabienes de ver ya inscripto el nombre del Tucumán entre los de los primeros héroes a quienes agradecerá la posteridad americana su libertad y su dicha." ${ }^{27}$
}

Pouco depois, a cidade recebe o título de "Sepulcro da Tirania", e se vê eximida da contribuição extraordinária instaurada em julho "por serviços prestados à pátria":

\footnotetext{
El dedicado patriotismo de esta Ciudad, sus grandes esfuerzos, y el ardiente empeño que ha mostrado siempre, y muy particularmente el 24 de septiembre último, los vivos deseos de su libertad contra los insultos y agresiones del tirano exigen imperiosamente ciertas consideraciones a su favor, que es indispensable concederlas para distinguirla de otros pueblos y ciudades que ni se han hallado en aquel caso, ni han hecho tantos sacrificios. ${ }^{28}$
}

Esse exemplo permite sublinhar o que se produz no patriotismo das cidades: uma emulação, uma manifestação de diferentes qualidades, que visa a obter em retorno honras e privilégios. A representação da comunidade, no sentido antigo do termo, conjuga a afirmação de uma identidade particular ao alinhamento a critérios válidos para todas as cidades 
(submissão às autoridades, coragem, generosidade, fidelidade). 0 contexto revolucionário e bélico dos anos 1810-1812 apenas reforça a implicação das cidades nesse elo patriótico comum.

0 caráter particular do engajamento que acabamos de descrever permite sugerir que ele pode servir de paliativo à representação política propriamente dita. De fato, as manifestações e os objetivos do patriotismo diferem daqueles que se produzem nas eleições: num caso, trata-se essencialmente de defender seu Rei, depois, sua mediação, por meio de doações; no outro, trata-se de defender seus interesses por meio de uma mediação, escolhendo o porta-voz mais digno da confiança que a comunidade the confere. Mas num e noutro caso, são os recursos da representação antiga que estão em jogo, e que se exprimem por meio da questão das virtudes e da idoneidade. Eleger um deputado dotado das qualidades requisitadas não é apenas uma maneira de ver seus interesses bem defendidos, é garantir que ele transmitirá uma "boa imagem" da cidade. 0 "representante" da cidade o é no sentido pleno do termo: ele é sua encarnação, e é suposto que reflita as virtudes de sua comunidade de origem. Ora, a mesma lógica se produz nas demonstrações de patriotismo; todas qualificam a comunidade de onde elas emanam e a tornam dignas de elogios e de recompensas. Por isso mesmo, o patriotismo constitui, para a cidade, um meio de obter vantagens ou de ver suas reinvindicações levadas em conta, de maneira talvez mais eficaz que as ações de um deputado. No fundo, não em seu fim, mas em suas consequências, a ação patriótica se une à deputação.

0 contexto de guerra faz o patriotismo despontar como o vínculo mais forte existente entre o novo poder e as cidades. Pela invocação patriótica, apoiando-se nos recursos antigos da fidelidade às autoridades e ao exemplo ilustre de Buenos Aires, os dirigentes obtêm das cidades a ajuda de que necessitam para refugar os ataques realistas. De sua parte, as cidades veem nisso um meio mais seguro que a eleição de um deputado para mostrar suas qualidades e obter um certo número de distinções. É por isso que o patriotismo, tanto em seus valores quanto em suas manifestações, pode funcionar, durante este periodo, como um substituto da representação política.

Resta-nos analisar o conteúdo propriamente dito desse patriotismo, insistindo na onipresença do elemento religioso, tanto em suas manifestações quanto em suas temáticas. A religião católica é não somente indissociável do sistema de valores e de crenças propagados pelo novo imaginário patriótico, mas ela consiste, a despeito das mutações da soberania, no principal auxiliar do poder político.

II - O lugar da religião na formação de uma consciência coletiva Refletir sobre o papel que desempenha a religião católica na difusão do "espírito público" e na maneira em que esta liga-se ao patriotismo das cidades leva a considerar, em primeiro lugar, a questão dos atores que veiculam esta linguagem, antes de estudar o conteúdo propriamente dito dos discursos, as duas dimensões revelando o ajuste fino do religioso e do político.

TANZI, Héctor José. Interpretación de la Revolución de Mayo según oraciones de sacerdotes contemporáneos del suceso. Investigaciones y Ensayos, n.14, 1973, p.557-576; . El clero patriota y la

Revolución de Mayo, Revista de Indias, v.37, n.147-148, 1977, p.141-158.

\section{a) 0 papel dos curas na difusão da propaganda patriótica}

No quadro da mobilização patriótica e da propagação do "espírito público", um papel particularmente importante pertence, com efeito, aos curas. ${ }^{29}$ Como lembra Roberto Di Stefano, no momento das reformas bourbônicas, o poder real tinha por ambição transformar o clero secular (clero paroquial) 
Oficio del Gobernador-Intendente al Vicario General, 10/09/1812, AGN Gob. Men., X-5-5-3.

31

Informe del Ayuntamiento de Córdoba al gobernador, 13/05/1812, AGN Gob. Men., X-5-5-2.

32

Oficio del Gobernador-Intendente al Vicario General, 10/09/1812, AGN Gob. Men., X-5-5-3.

33

Circular del Obispo de Córdoba a su Diocesis, 9/06/1812, AGN Gob. Cba., X-5-5-2.

34

Esta mudança na liturgia se efetua em todas as dioceses tocadas pela revolução (Salta, Buenos Aires e Córdoba). Cf. TONDA, Américo. La Iglesia argentina incomunicada con Roma. Santa Fe: Castellví, 1965.

35

Oficio del Superior Gobierno al Obispo de Córdoba, 28/07/1812, Universidad de Córdoba, Instituto de Estudios Americanistas "Mgr. Pablo Cabrera" (IEA), doc. n 9107; Obispo de Córdoba al Superior Gobierno, 20/08/1812, AGN Gob. Men., $\mathrm{X}-5-5-2$.

36

Tornada doutrina oficial da Monarquia espanhola no último terço do século XVIII, o regalismo tem por objetivo distinguir os direitos do soberano (regalia) daqueles do papa, de colocar as instituições eclesiásticas sob o controle da Coroa e de fazê-los participar da exaltação ao poder real. Cf. DE LA HERA, Alberto. El regalismo borbónico en su proyección indiana. Madri: Rialp, 1963; HERMANN, Christian. L'Église d'Espagne sous le patronage royal (1476-1834). Madri: Casa de Velázquez, 1988; CHIARAMONTE, José Carlos. La Ilustración. Op. Cit. num corpo de agentes do Estado encarregados de "civilizar" os fiéis, isto é, estabelecer pontes entre a cultura das elites e a cultura popular. 0 novo regime se inscreve na mesma tendência ao confiar aos membros do clero, e sobretudo aos curas, o dever de difundir e sustentar o discurso patriótico nas consciências.

A partir de junho de 1812, estes são convidados a dedicar todo ou parte de seus sermões à explicação ou exaltação dos princípios revolucionários:

El Excelentísimo Superior Gobierno de las Provincias Unidas del Río de la Plata exhortó a los Reverendos Obispos de la comprensión de su mando a que ordenasen en sus respectivas diócesis que en toda [prédica] o sermón, con cualquier objeto que fuese, se había de procurar persuadir (sic) la legitimidad de nuestro Gobierno y la justicia con que trabajamos por la consolidación del sistema adoptado y destitución de los tiranos, convenciendo a todo ciudadano de la obligación en que se halla de concurrir aun con su vida a defender los imprescriptibles derechos que atrozmente se nos quieren usurpar. También dispuso la Superioridad que en el santo sacrificio de la misa se rogase por la Santa y piadosa causa de nuestra libertad. ${ }^{30}$

0 Prior dos Dominicanos de Mendoza, frei Matías José del Castillo, dedica, assim, as preces da Quaresma de 1812 a explicar às suas ovelhas o direito do homem, a soberania dos pueblos, a liberdade e seus limites, 0 amor pela pátria e a obediência devida ao governo. ${ }^{31}$ Sublinhemos que, se nada proíbe os curas de agir zelosamente, estes não dispõem de qualquer latitude real, uma vez que o conteúdo "patriótico" dos sermões era fixado pelo poder central. Como o mostra a citação acima, eles deviam justificar os atos do regime revolucionário e firmar em suas consciências a noção de "sacrifício pela Pátria", a fim de que esta não viesse a carecer de recrutas. Este zelo não era, contudo, seguido em todos os lugares, nem por todos: durante o mês de novembro de 1812, constatando que a prática dos "pontos patrióticos" não parece nem um pouco cumprida, o governador lembra ao clero de Mendoza seu dever. ${ }^{32}$

Considerando-se a importância dos curas na formação das consciências, a atitude dos altos dignatários também era vigiada de perto. No início de 1812, o governo anistia o bispo de Córdoba, Rodrigo Antonio de Orellana, que fora exilado durante algum tempo pela adesão duvidosa à revolução. Por solicitação dos dirigentes, o bispo aceita:

Promover la unión, y fraternidad de nuestros amados fieles en J.C. con el importante objeto de extinguir las discordias que se propagan en estas provincias a pesar de hallarnos todos unidos todos con los estrechos vínculos de la religión santa que profesamos, y de la Soberanía, y Gobierno que reconocemos. ${ }^{33}$

Em seguida, Orellana ordena que se introduza, nas preces e litanias que seguem a grande missa dominical, a cláusula "ut australis Americae Provincias Unitas", que reconhece formalmente a existência da pátria diante do mundo. ${ }^{34}$ Depois de tê-lo felicitado calorosamente, o governo vai mais longe, sugerindo uma forma mais extensa a introduzir na própria liturgia. 0 bispo aceita acrescentar esta fórmula no fim do ofício, aumentada por algumas palavras que sublinham a colusão dos poderes civis e religiosos: "et justam nostra libertatis causam tum chritianam tum civilem protege pacem et salutem". ${ }^{35}$

Essa cooperação dos poderes civis e religiosos, herdada do regalismo ${ }^{36}$ é reforçada por uma analogia nada acidental entre o discurso revolucionário e os valores cristãos: os temas do sacrifício, da união e da 
37

Muitos dentre eles foram publicados no volume de CARRANZA, Adolfo. El clero argentino de 1810 hasta 1830. Buenos Aires: Imprenta de M. A. Rosas, 1907.

38

Oficio del cabildo de Salta al Superior Gobierno, 20/06/1812, AGN, Gobierno de Salta (Gob. Salta), $\mathrm{X}-5-7-3$.

39

Universidad de Córdoba, Instituto de Estudios Americanistas "Mgr. Pablo Cabrera" (IEA), doc. $n^{\circ}$ $11765-11770$

Oración patriótica que dijo el 25 de Mayo de 1817 en la ciudad de Tucumán el doctor Felipe Antonio de Iriarte. Cf. CARRANZA, Adolfo. Op. Cit, p.197-221.

41

Oficios del cabildo de Tucumán, 31/08/1813 et 20/11/1813, AGN Gob. Tuc., X-5-10-2.

42

DI STEFANO, Roberto. Lecturas bíblicas de la Revolución de independencia (1810-1835). Anuario de Historia de la Iglesia, n. 12, 2003, p.201-24.

43

Sermon de fray Pantaleon García, Córdoba, 25/ mai/1814. Cf. CARRANZA, Adolfo. Op.Cit., p.89-105. obediência às autoridades civis fazem parte, desde há muito, do registro recorrente dos sermões. ${ }^{37}$ Estes são, portanto, suportes decisivos da difusão da mensagem revolucionária, e por vezes se assumem como verdadeiros manifestos políticos, como aquele que frei Gervasio Monterroso pronuncia em 25 de maio de 1812 em Salta, e que o cabildo propõe publicar "para que sirva de instrumento público contra los enemigos de nuestra causa" ${ }^{38}$ Porque elas atingem muito mais pessoas que os impressos, as preces podem ser consideradas como os principais elementos de uma "guerra do verbo", que constitui o pendant ideológico da luta armada.

A construção retórica desses sermões está inteiramente baseada nos catecismos da época. Por exemplo, durante a quaresma de 1816, o reitor (cura rector) da catedral de Córdoba recebe a ordem de comentar, toda quinta-feira, um dos direitos principais: a liberdade, a propriedade, a segurança e a igualdade. Para cada um dentre eles, começa por dar uma definição teológica e moral, antes de a ilustrar com uma referência ao patriotismo americano. Assim, no caso da liberdade: "la libertad es el uso que hace el hombre de la tercera facultad de su alma, que es la voluntad. (...) para ser yo patriota libre, me es forzoso ser virtusos, honrado y religioso, asi en mi vida, en mis sentimientos, como en mis acciones y costumbres". 39

Uma variante consiste em enunciar uma máxima geral ("Os princípios políticos são necessários"), sobre a qual dá-se um exemplo edificante (a Roma antiga) e a partir da qual tira-se uma conclusão igualmente edificante ("Todo lo que no tiene relación con la felicidad común es antipolítico y detestable" ). É igualmente utilizada a técnica, muito comum nos catecismos, de "questões didáticas", transposta aqui aos "pontos patrióticos". À questão: "Antes de [la revolución], ¿a quién obedeciais?" é proposta uma resposta: " A una deidad que os dominó por la fuerza, y que no os conocía, ni os amaba", e uma conclusão: "¿A quién obedeceis hoy? ¡Qué diferencia, ciudadanos! Vosotros mismos distribuis los destinos. La soberanía del pueblo está en posesión de sus derechos".40 Outros efeitos retóricos são igualmente utilizados para esses fins didáticos, assim como o procedimento de mise en scène no interior do discurso. Assim, o projeto de festa que apresenta o cabildo de Tucumán em 1813 esboçava um quadro da cidade dominada por duas forças que se enfrentam: de um lado a espada ameaçadora do tirano, do outro, a mão protetora de Deus. A vitória de Las Piedras simboliza, evidentemente, a intervenção divina, "o imenso exército (das forças régias) se evaporando num instante, como fumaça".41

Enfim, esses sermões contêm numerosas referências históricas, que pertencem a uma bagagem cultural das Luzes católicas. Como o mostrou bem Roberto Di Stefano, a mais frequente é a referência à História Santa e, particularmente, ao Antigo Testamento. Este oferece um espelho no qual se reflete a História da Independência, permitindo legitimá-la enquanto implementação do projeto divino..$^{42} \mathrm{~A}$ identificação dos americanos à escravidão e depois ao êxodo dos hebreus é, assim, sugerida sem cessar, como o mostra este comentário sobre as festas judias em um sermão de maio de 1814: a "criação do mundo" é assimilada à conquista da América, "la Pascua, por el éxodo de Egipto", a independência e o "Pentécostes, por la ley dada en el monte", com a reunião da Assembleia Geral Constituinte de $1813 .{ }^{43} \mathrm{~A}$ segunda referência remete à antiguidade profana: os grandes impérios, o Egito, Cartago, Grécia e Roma, são utilizados para invocar as "lições da História". Não apenas abundam de episódios edificantes, mas, na medida em que todos eles acabaram por 
44

VERDO, Geneviève. La bannière, le sabre et le goupillon. Les cérémonies patriotiques au Río de la Plata. Revue Historique, v.296, n.2, 1997, p.401-429.

45

GARAVAGLIA, Juan Carlos. A la Nación por la fiesta: las fiestas mayas en el origen de la nación en el Plata. Boletín del Instituto de Historia Argentina y Americana "Dr. Emilio Ravignani, 3a. serie, n. $22,2^{\circ}$ sem. 2000, p.73-100.

46

Circular de la Junta Gubernativa, 24/01/1811, AHM Ind., 602-27.

47

BAYLE, Constantino. Los cabildos seculares en la America española, Madri, 1952.

48

Circular de la Junta Gubernativa, 24/01/1811, AHM Ind., 602-27.

49

WILDE, Ana. Op. Cit.

Oficio del gobernador de Córdoba, 9/09/1812, AGN Gob. Cba., X-5-2-4.

conhecer a decadência e a tirania, mostram, a contrario, o vínculo que existe entre a liberdade e a virtude.

Esses exemplos servem para fundar uma "nova História", a evidenciar, por um jogo de analogias, uma versão dos eventos orientada pela perspectiva da revolução e da independência das Províncias Unidas. Pode-se falar desses sermões como verdadeiros "catecismos patrióticos", tendo por finalidade amparar os espíritos em novas regras de conduta moral conformes aos princípios do direito natural e reinterpretadas pela ideologia revolucionária. De modo mais geral, esses discursos são inseparáveis do âmbito nos quais eles são pronunciados, aquele das festas religiosas e patrióticas.

\section{b) 0 elemento religioso nas cerimônias patrióticas}

Como vimos, as cerimônias patrióticas ${ }^{44}$ são uma das principais ocasiões a conjugar a promoção do "espírito público" e o zelo patriótico das cidades. A partir de 1810, para além das festas religiosas, celebram-se os episódios importantes ligados ao estabelecimento do novo regime - a começar pelo 25 de maio -, e, cada vez mais, os eventos ligados à guerra.

A principal iniciativa do poder revolucionário é a criação das Festas de Maio..$^{45} 0$ propósito assinalado a esse novo ritual é, muito precisamente, aquele de uma comemoração. Como o explica a circular da Junta de 24 de janeiro de 1811: "Como los días 24 y 25 de Mayo forman la época grande en la Historia de la América, se hace preciso transmitir esta memoria a la posteridad con una impresión eterna".46

Entretanto, o texto não prevê ritual inédito, que traduziria nos gestos e nos símbolos o surgimento de um tempo novo que se procura inserir nas consciências. 0 aniversário do 25 de Maio conserva, ao contrário, o protocolo das antigas cerimônias, particularmente a procissão do Estandarte Real. 0 texto precisa que a "pompa e a solenidade" da nova celebração devem ser iguais àquelas implementadas na festa do Santo Padroeiro, que é de longe a mais importante para as cidades ${ }^{47} \mathrm{Em}$ contrapartida, esta se encontra reduzida " a la sóla función de Iglesia, con misa y sermón de estilo, pero de ningun modo al paseo del Estandarte." ${ }^{48}$ Esta modificação é eloquente: ao conservar a procissão do Estandarte como símbolo da fidelidade às autoridades legítimas, a adesão ao novo regime intenta substituir aquela devida ao monarca. Deste modo, como sublinha Ana Wilde, o poder central desvia, em seu proveito, um ritual de adesão fortemente amparado nas práticas locais. ${ }^{49}$

Nos anos seguintes, as celebrações, cada vez mais ligadas a eventos militares, mantêm um aspecto tradicional, com a reunião dos habitantes na praça e o desfile em cortejo das corporações que vão à igreja. Com efeito, se regozijos profanos sempre ocorrem à tarde, a cerimônia religiosa permanece o episódio central do dia. Não se trata, às vezes, de mais do que uma simples benção, na ocasião, por exemplo, da chegada de um carregamento de armas à cidade. Mas, quando a festa ocorre em uma data importante, é uma missa solene com o Te Deum que constitui o tempo forte da celebração. A orientação revolucionária não muda nada, o elo patriótico inscrevendo-se inteiramente no registro religioso. Isso se mostra especialmente pelas práticas espontâneas de devoção que os relatos descrevem à margem dos atos oficiais: o governador de Córdoba relata em 1812, que "[su] Pueblo que, lleno de su santo entuciasmo, dirigía publicamente sus votos al Dios de los Ejercitos en acción de gracias por tan singular beneficio [la victoria que han logrado las armas de la Patria contra el General Goyeneche]"50. 
51

Sermón de Pedro Ignacio de Castro Barros, 25/051815. Cf. CARRANZA, Adolfo. Op. Cit. p.276-289.

52

Ibidem.

53

DI STEFANO, Roberto. La Revolución de las almas: religión y política en el Río de la Plata insurrecto (1806-1830). In: Los curas de la Revolución. Op.Cit. p.21.

54

HOBSBAWM, Éric. Nations et nationalismes depuis 1780. Paris: Gallimard, 1992. p.111.

55

Domingo Garcia al gobernador de Mendoza, 18/05/1813; Fray Mariano Sayos al mismo, 21/08/1813, AHM Ind., 60-15 et 24. Sobre 0 papel do clero na Independência argentina, Cf. PIAGGIO, Agustín. Influencia del clero en la independencia argentina (1810-1820). Barcelona: L. Gili, 1912; GARCÍA DE LOYDI, Ludovico. Los capellanes del ejército. Buenos Aires: Dirección de Estudios Históricos, 1965.

56

ORTEMBERG, Pablo. Las vírgenes generalas: acción guerrera y práctica religiosa en las campañas del Alto Perú y el Río de la Plata (1808-1818). Boletín del Instituto de Historia Argentina y Americana "Dr. Emilio Ravignani". $3 a$. serie, n.35/36, 2012, p.11-41.

57

Carta de Belgrano a San Martin, 6/04/1814. In: Documentos del Archivo de San Martín, Buenos Aires, 1910-1911, t.2, p.43.
Além daquela de canalizar a emoção popular, a principal função das cerimônias patrióticas é a de conferir um valor transcendental às referências e às principais figuras da revolução. Esse processo de sacralização passa, antes de tudo, pelo ritual, que permanece inalterado em comparação com o antigo regime: ora, o respeito escrupuloso pelo protocolo, naquilo que concerne o decoro, o lugar dos participantes e os gestos a observar, é uma operação que gera solenidade $e_{1}$ a partir disso, legitimidade, no sentido jurídico do termo, relacionando-se às formas precisas a pôr em causa a vitalidade de um ato. Mas o ritual não basta para sacrilizar o novo objeto que é a Revolução: segundo a expressão de Pedro Ignacio de Castro Barros, em 25 de maio de 1815, "aos fastios da cidade devem se unir as ideias", ${ }^{11}$ as palavras também participam dessa inscrição na transcendência. $\dot{E}_{\text {, assim, função dos sermões }}$ sacralizar certas figuras ou certos objetos, convocados a se tornar marcas importantes da memória revolucionária. Os oficiais e soldados vitoriosos são, desse modo, elevados à condição de heróis: após Maipu, San Martín será declarado imortal; sua espada, comparada a de David e declarada invencivel, será depositada sobre 0 altar. Os eventos políticos e militares são igualmente sacralizados: assim, o sermão de 25 de maio de 1815 em Tucumán comporta um longo desenvolvimento que aloca o vigésimo quinto dia do mês numa continuidade que vai da História Santa (a fuga do Egito teria ocorrido no vigésimo quinto dia do mês de Adar) à História Cristã (Jesus Cristo nascido num 25 de dezembro, Constantino feito imperador num 25 de julho) e à História da Monarquia espanhola (Philippe $V$ vitorioso num 25 de abril) ${ }^{52}$. A data do 25 de maio encontra, assim, seu lugar na história universal, que conjuga História profana e História santa. ${ }^{53}$

\section{c) 0 fundamento religioso do patriotismo}

0 patriotismo revolucionário e militar que se afirma a partir de 1812 tem, portanto, pouco a ver com a invenção de uma "religião civil", segundo a fórmula rousseanista retomada por Eric Hobsbawm. ${ }^{54}$ Como vimos, as cerimônias indicam, ao contrário, a onipresença do elemento religioso na definição do patriotismo. Ademais, a propaganda patriótica é largamente confiada aos membros do clero, que organizam as manifestações religiosas em torno da guerra, tais como as ações de graça ou as preces em favor das armas da pátria. ${ }^{55}$ As vitórias se inscrevem na perspectiva de uma história governada pela Providência; elas são interpretadas como o signo da proteção divina concedida aos patriotas e à revolução. É frequente que o elemento divino seja equiparado aos atributos da guerra: assim, encontram-se nos textos incontáveis menções ao "Deus dos exércitos", ao "Senhor das batalhas" ou às "Virgens generais". 56

Uma carta de Belgrano a San Martín, no momento em que este último assume o comando do Exército do norte, explicita certos aspectos da relação nada acidental que os patriotas estabelecem entre a guerra e a religião. Esta permite, com efeito, que a guerra seja aceita pelas populações locais:

La guerra alli [en el Interior], no sólo la ha de hacer usted con las armas, sino con la opinión, afianzándose siempre ésta en las virtudes naturales, cristianas y religiosas; pues los enemigos nos la han hecho llamándonos herejes, y sólo por este medio han atraido las gentes bárbaras a las armas, manifestándoles que atacábamos la religión. ${ }^{57}$ 
Oficios del cabildo de Tucumán, 31/08/1813 et 20/11/1813, AGN Gob. Tuc., X-5-10-2.

61 VIGUERIE, Jean de. Op. Cit

Oficios del cabildo de Tucumán, 31/08/1813 et 20/11/1813, AGN Gob. Tuc., X-5-10-2.

63

DI STEFANO, Roberto. Lecturas bíblicas. Op. Cit.

De acordo com ele, a mesma estratégia deve ser adotada para manter a disciplina no exército:

"He dicho a usted lo bastante (...); añadiré únicamente que conserve la bandera que le dejé y que la enarbole cuando todo el ejército se forme, que no deje de implorar a nuestra señora de las Mercedes, nombrándola siempre "nuestra generala" y no olvide los escapularios a la tropa. Deje usted que se rían, los efectos le resarcirán a usted de la risa de los mentecatos que ven las cosas por encima. Acuérdese usted que es un general cristiano, apostólico romano, cele usted de que en nada, ni aun en las conversaciones más triviales se falte al respeto de cuanto diga a nuestra santa religión $[. . .]^{58}$

0 projeto de Tucumán de criar uma festa cívico-religiosa para comemorar a batalha de Las Piedras se inscreve nessa consagração da vitória militar. A coincidência da vitória com a festa da Virgem das Mercedes reforça o culto consagrado a esta, enquanto o título de "General do Exército" que Ihe confere Belgrano a vincula indiscutivelmente ao triunfo da guerra. 0 projeto de festa anual apresentado pelo cabildo ao poder central consiste em dar à Virgem o título de vice-patrona da cidade (patrona menos principal de la ciudad), em homenagem ao "distinguido beneficio, que en igual día recibió la Patria de su Santísima mano, destruyendo y aniquilando las legiones enemigas que sacrílegamente atacaban los derechos sagrados del hombre y de la libertad civil"59 contempla a celebração de uma missa solene, pela manhã, na igreja consagrada a esta Virgem, depois uma comemoração, à tarde, no campo de batalha de Las Piedras. ${ }^{60}$ Por intermédio da festa religiosa, o evento militar é, assim, consagrado e incorporado aos anais municipais. 0 aspecto notável do projeto reside não apenas na reinterpretação patriótica de um culto religioso mas, igualmente, na apropriação, pela cidade, de um evento que diz respeito à pátria inteira. É sem dúvida esse último aspecto que explica que o poder central se oponha firmemente ao projeto, recusando a Tucumán, in fine, o direito de adquirir posição superior às demais cidades.

No sentido inverso, o próprio patriotismo tende a se tornar uma espécie de culto: ${ }^{61}$ a causa patriótica é constantemente apresentada como "sagrada"; as datas das vitórias juntam-se àquelas das jornadas revolucionárias no calendário das cerimônias, a par com as festas religiosas. A percepção de conjunto é aquela de uma História cíclica, da qual a revolução e a guerra constituem apenas um episódio. As perspectivas do culto patriótico unem-se, assim, àquelas da religião, o futuro da revolução constituindo uma linha de horizonte na qual a História profana tende a se confundir com o julgamento último:

\footnotetext{
La acción del 24 de septiembre (...) es una reproducción de aquel divino amparo, que deben gravar en sus corazones y anales los hijos de la Patria, para empeñar la cristiana devoción de las edades venideras. Tan cristiano monumento electrizará los ánimos, cuando la vuelta de los tiempos cierre el camino de los sucesos, por grandes que sean. ${ }^{62}$
}

Nada está mais distante de uma visão linear da História, na qual os fatos humanos transcenderiam o sagrado; a luta pela pátria é, ao contrário, pensada como um episódio essencial da História Santa, uma reconciliação entre os destinos do homem e o projeto divino. ${ }^{63}$

Durante os anos 1812-1814, a mobilização das províncias do interior caminha ao lado de uma promoção do "espírito público", que deveria 
É importante precisar, todavia, que os eclesiásticos estão divididos em diversas correntes de opinião, e que a orientação conservadora do regime, vinculada ao contexto de guerra ao longo dos anos 1812-1815, a conduz a se apoiar nos elementos mais conservadores desse clero. garantir sua coesão moral e material. 0 reflexo de defesa patriótica que as cidades já manifestaram durante o período $1806-1810$ a favor da monarquia ressurge com força, mas o território a defender está, neste momento, circunscrito aos limites do vice-reino, ou aos da América patriota. Essa adesão à causa se exprime essencialmente por meio do ritual e pela linguagem da religião católica, esta constituindo o ponto de encontro e de fusão entre o "espírito público", promovido a partir da cúpula do poder, e 0 patriotismo local das cidades. Essa identidade patriótica plural, ao mesmo tempo militar, religiosa e política, constitui um vínculo poderoso entre as diversas comunidades e serve, nesse sentido, de substituto a uma representação política deficiente.

Guerra, pátria e religião encontram-se, portanto, em estreita ligação no coração das cerimônias cívicas e da cultura revolucionária que se impõem, à altura, no Rio da Prata. 0 projeto de festa do cabildo de Tucumán aparece, nesse sentido, como exemplo paradigmático, mostrando a imbricação desses três elementos. Em sua dimensão profana, a guerra é vista como o sacrifício necessário dos patriotas para salvar a revolução; a pátria é, então, provisoriamente identificada à luta armada. Mas a isso se junta, na dimensão sagrada, o tema da proteção divina: no caso de Tucumán, a vitória de Las Piedras é naturalmente atribuída à proteção da Virgem das Mercedes. Largamente explorada pelas celebrações e pelos sermões, essa articulação permite justificar a busca de uma guerra que se apresente como inscrita no projeto divino. A vontade divina, invocada repetidamente, justifica os princípios profanos de legitimação dos novos poderes e a adequação de seus detentores, que são as autoridades civis e militares.

Como vimos, a promoção deste "espírito público" é largamente confiada aos membros do clero e, no conjunto, estes se mostram aptos a cumprir a tarefa que Ihes foi confiada. Celebrando os tempos fortes da revolução, exaltando suas virtudes cívicas e encorajando suas ovelhas quanto às certezas da felicidade por vir, os curas aparecem, assim, com os oficiais, como os melhores agentes do patriotismo revolucionário. Ademais, durante esse período de centralização do poder, a urgência da guerra e sua justificação religiosa têm por consequência mitigar a mensagem revolucionária, estruturando-a em torno de valores bastante conservadores: ${ }^{64}$ primado da unidade, respeito pela hierarquia e pelas autoridades, obediência e abnegação podendo ir até ao sacrifício. Mais ainda, nesse contexto, a religião desempenha um papel de ponte entre o "espírito público" e o patriotismo local, permitindo reforçar a adesão das cidades ao poder central e articular, num projeto comum de forte tonalidade providencialista, as identidades plurais dos pueblos e a "causa geral" da revolução.

Tradução: Luis César de Sá Júnior 